\title{
Hysteroscopic treatment of retained placental tissue: a case report
}

\author{
Daniilidis Angelos ${ }^{1,2^{*}}$ (D), Liberis Anastasios ${ }^{1}$, Papandreou Panagiotis ${ }^{3}$, Sidiropoulos Konstantinos ${ }^{3}$, \\ Pratilas George ${ }^{1}$ and Dinas Konstantinos ${ }^{1}$
}

\begin{abstract}
Retained placenta tissue is a rare condition, and its diagnosis and surgical treatment are often challenging. Conventionally, the surgical management of such cases is largely performed using blind dilation and curettage. Our case demonstrates that the successful complete removal of retained placental tissues can be achieved with operative hysteroscopy with minimal use of electrosurgery in order to minimize the short- and long-term complications. This was achieved using the loop of the bipolar resectoscope as a curette performing cold dissection.
\end{abstract}

Keywords: Retained placental tissue, Placental remnants, Hysteroscopy, Resectoscope, Hysteroscopic tissue removal, Retained products of conception (RPOC)

\section{Introduction}

Retained placental tissue after vaginal or cesarean delivery is a rare condition and occurs in 0.6 and $3.3 \%$ of patients [1]. The optimal management of RPOC necessitates complete evacuation of the retained products with minimal endometrial trauma. Surgical management options of this condition include blind curettage, hysteroscopic resection, and hysteroscopic morcellation [2]. The failure of an optimal procedure is associated with significant shortand long-term complications. Short-term complications include incomplete evacuation and need for repeat procedure, infection, sepsis, hemorrhage, and uterine and cervical trauma. Long-term complications include abnormal placentation, formation of intrauterine adhesions, and adverse reproductive outcomes [3].

\section{Case report}

A 40-year-old nulliparous woman with no previous gynecological operations underwent at 39 weeks of

\footnotetext{
* Correspondence: angedan@hotmail.com

'2nd Department of Obstetrics and Gynecology, Hippokratio General

Hospital, School of Medicine, Aristotle University of Thessaloniki, Thessaloniki, Greece

${ }^{2}$ Thessaloniki, Greece

Full list of author information is available at the end of the article
}

gestational age a caesarean section due to breech presentation. The mother's body mass index (BMI) before cesarean section was 26, and her body temperature, blood pressure, and heart rate were within normal limits $\left(36.8^{\circ} \mathrm{C}, 128 / 77 \mathrm{mmHg}\right.$, and 79 beats per minute (bpm), respectively). The cesarean section was standard and uncomplicated. Twenty-four hours postnatally, she developed postpartum hemorrhage (PPH). She was managed medically with Syntocinon and ergometrine initially followed by dilation and curettage. Retained placental tissue was removed. Hospitalization was uneventful, and she was discharged home 4 days after delivery.

Forty days later, on her routine postnatal follow-up, she complained for persistent spot bleeding. Transvaginal ultrasound revealed a hyperechoic inhomogeneous mass in the uterine cavity, within the fundus and posterior part of the endometrial cavity infiltrating also myometrium up to $10 \mathrm{~mm}$ from uterine serosa, suggestive of retained products of conception (RPOC). The mass measured $18 \times 18 \mathrm{~mm}$ in diameter, and color Doppler ultrasound (US) excluded vascularization (color score 1). Both annexes were normal. Serum levels of beta-human chorionic gonadotrophin ( $\beta$-hCG) were negative. Hysteroscopic removal of the retained tissue under ultrasound 
guidance was decided. The procedure was performed under general anesthesia using a 26-F resectoscope (Karl Storz, Tuttlingen, Germany) fitted with a bipolar 4-mm cutting loop. The woman was in gynecologic position, and the procedure was carried out after cervical dilation using Hegar's candles. Hysteroscopy revealed a mass which grossly measured $1.5 \times 1.5 \times 2 \mathrm{~cm}$. In order to separate and remove gently and selectively the placental remnant from the underlying endometrium, we used the loop of the bipolar resectoscope as a curette performing cold dissection. During the procedure, we minimized the use of electrosurgery, and under transabdominal ultrasound guidance, remnants were successfully removed as close as the uterine serosal border. Our aim was to minimize thermal damage to the endometrium in order to reduce the risk of formation of intrauterine adhesions, perforation, and bleeding. Figure 1 demonstrates the hysteroscopic view of the retained placental tissue and the ultrasound image of the uterus before the operation. The removed material was sent to histological examination and the histological report confirmed our diagnosis. The procedure lasted 23 minutes. At the end of the surgical procedure, the cavity appeared to be empty. Total blood loss during the procedure was less than $50 \mathrm{ml}$ with total normal saline deficit of $500 \mathrm{ml}$ (total in $5800 \mathrm{ml}$ and total out $5300 \mathrm{ml}$ ). The patient was fully recovered, and follow-up was uneventful. Two months after the operation on routine transvaginal ultrasound examination, a normal looking endometrial cavity was identified. Patient had no menstruation yet, due to breastfeeding.

\section{Discussion}

Retained products of conception (RPOC) may occur after miscarriage, pregnancy termination, and vaginal or cesarean delivery [4]. One of the most important risk factors that may lead to RPOC is placenta accreta, defined as abnormal attachment to the myometrium either in whole or in part [5]. RPOC may lead to short- and long-term complications. Short-term complications include abdominal vaginal bleeding or spotting and infections, while long-term complications include Asherman's syndrome,

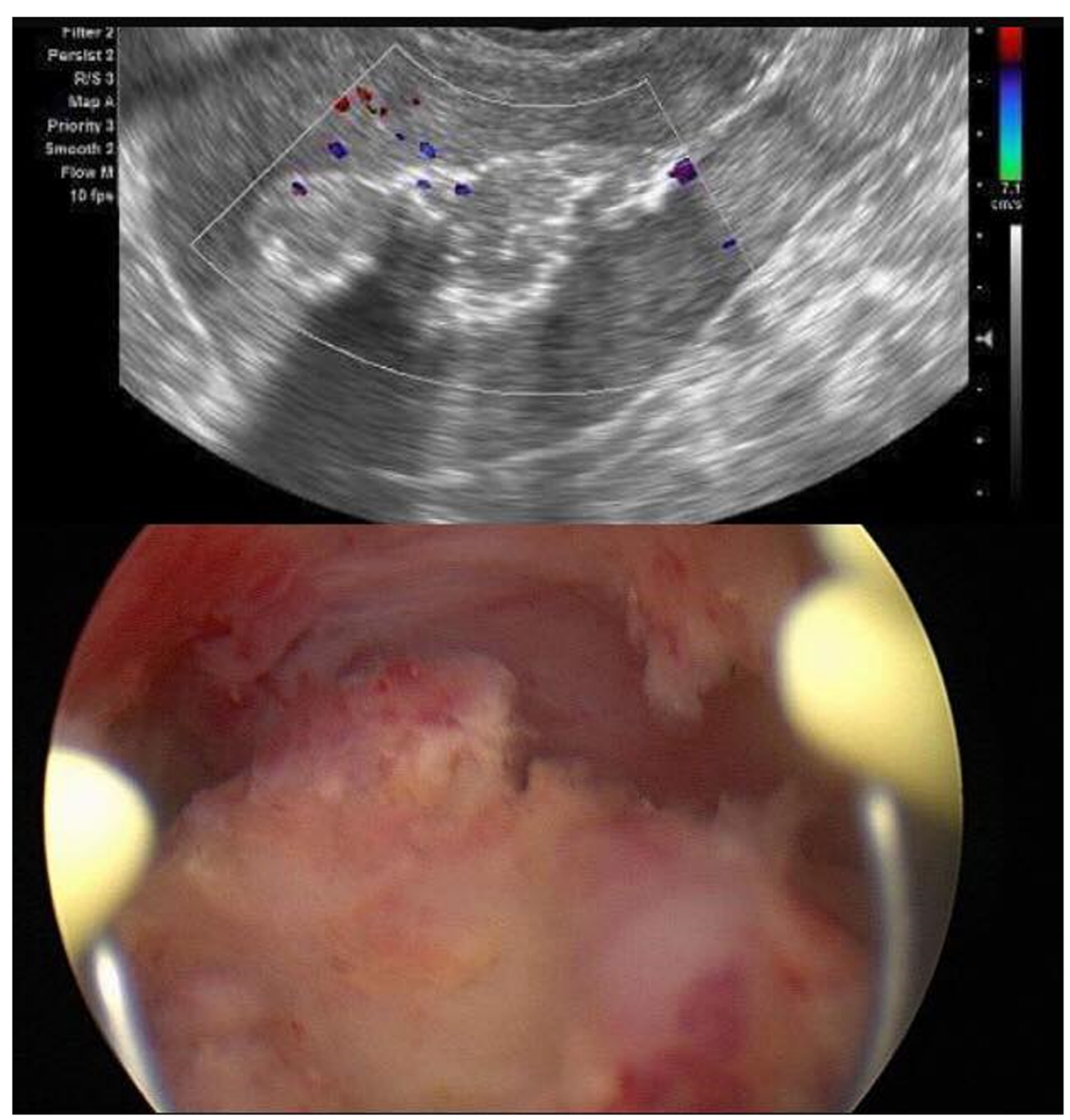

Fig. 1 Up: ultrasound image of the uterus before the operation. Down: hysteroscopic view of retained placental tissue 
infertility, miscarriages, and pregnancy complications such as placenta accreta [6]. Ultrasonography is useful in order to evaluate RPOC, although it is challenging to differentiate blood clots from RPOC. Among the sonographic features that may imply RPOC are endometrial mass, greater endometrial thickness (ET), and high endometrial vascularity. Endometrial mass is the most sensitive (79\%) and specific (89\%) feature for RPOC [7]. All in all, the diagnosis is based on the sonographic appearance of intrauterine echogenic material, on patient's symptoms and signs and on clinical findings [8].

Surgical management options of this condition include blind curettage, hysteroscopic resection, and hysteroscopic morcellation [2]. Conventionally, the surgical management of such cases is largely performed using blind dilation and curettage [3]. Though traditional, blind curettage may cause complications such as uterine perforation, incomplete evacuation with persistence of retained intrauterine products, and Asherman's syndrome [9]. On the other hand, blind curettage has shorter learning curve and preprocedure set up compared to the other methods and costs less in the short term [3]. More recently, hysteroscopic removal has been proposed in the literature as being a superior option to blind curettage. The major advantage of hysteroscopic removal is the possibility to selectively resect RPOC under direct visualization without affecting the adjacent endometrium. A recent meta-analysis included 326 cases of retained products of conception and compared the rates of complications following hysteroscopy and curettage. According to the results, hysteroscopy is superior to traditional curettage as it reduces the risk of uterine perforation and intrauterine adhesion and improved future reproductive outcomes [10]. However, the hysteroscopic technique of resection of the retained placental tissue may be challenging in the immediate postpartum period due to heavy vaginal bleeding and the risk of perforation [11]. Bland dissection with the tip of the resectoscope appears to be a quite safe approach with less risk of bleeding or perforation of the uterus. The goal of the method is to evacuate the cavity with minimal endometrial trauma avoiding the use of electrosurgery [10]. Furthermore, another important advantage of the hysteroscopic management of such cases compared with blind dilation and curettage is the preoperative accidental finding of uterine cavity malformations such as uterine septum [12].

Another safe alternative method which has gained popularity worldwide is the hysteroscopic morcellation of intrauterine pathology. The hysteroscopic morcellator consists of a set of two hollow tubes that fit into each other and rotate within each other. The tissue can be cut, shaved, and sucked. A recent randomized controlled trial found that hysteroscopic morcellation may be superior to loop resection in the removal of retained placental tissues [2].

\section{Conclusion}

Retained placenta tissue is a rare condition and needs accurate diagnosis and least treatment-related complications. Operative hysteroscopy seems to be superior to blind curettage as it allows the complete visualization of the uterine cavity and gentle tissue removal under direct vision. However, there are no clear guidelines for optimal treatment of RPOC; consequently, further research and randomized-controlled trials are needed in order to determine the gold standard treatment of this condition.

\section{Abbreviations}

BMI: Body mass index; bpm: Beats per minute; PPH: Postpartum hemorrhage; RPOC: Retained products of conception; US: Ultrasound; b-HCG: Beta-human chorionic gonadotrophin

\section{Acknowledgements}

N/A

Authors' contributions

All authors contributed to the selection of data and the presentation of the manuscript. The authors read and approved the final manuscript.

\section{Funding}

No funding to declare

Availability of data and materials

All data and material used are available

Ethics approval and consent to participate

N/A as it is a case report.

Consent for publication

Patient consented for the publication

\section{Competing interests}

The authors declare that they have no competing interests. This study was conducted without any financial support. The authors state that the views expressed in the submitted article are their own and not the official position of the institution or funder.

\section{Author details}

${ }^{1}$ 2nd Department of Obstetrics and Gynecology, Hippokratio General Hospital, School of Medicine, Aristotle University of Thessaloniki, Thessaloniki, Greece. ${ }^{2}$ Thessaloniki, Greece. ${ }^{3}$ Private Obstetric and Gynecology Clinic of Genesis, Thessaloniki, Greece.

Received: 3 April 2020 Accepted: 19 May 2020

Published online: 01 June 2020

\section{References}

1. Weeks AD (2001) The retained placenta. Afr Health Sci. Aug;1(1):36-41.

2. Lee MHM (2019) Surgical management of retained placental tissue with the hysteroscopic morcellation device. Gynecol Minim Invasive Ther. Jan-Mar; 8(1): 33-35.

3. Sutherland NSV, Rajesh H (2018). The intrauterine Bigatti Shaver system: an alternative option for focal retained products of conception. Case Reports in Obstetrics and Gynecology. Nov 21;2018:1536801. doi: https://doi.org/10. 1155/2018/1536801.

4. Westendorp IC, Ankum WM, Mol BW, Vonk J (1998) Prevalence of Asherman's syndrome after secondary removal of placental remnants or a repeat curettage for incomplete abortion. Hum Reprod. 13:3347-3350

5. Guarino A, Di Benedetto L, Assorgi C, Rocca A, Donatella C (2015) Conservative and timely treatment in retained products of conception: a 
case report of placenta accreta retention. Int J Clin Exp Pathol. 8(10):1362513629

6. Yu D, Wong YM, Cheong Y, Xia E, Li TC (2008) Asherman syndrome--one century later. Fertil Steril. 89:759-779

7. Lin YH, Cheng YY, Ding DC (2018) Hysteroscopic management of retained products of conception. Gynecol Minim Invasive Ther. Jul-Sep; 7(3): 133135.

8. Ustunyurt E, Kaymak O, Iskender C, Ustunyurt OB, Celik C, Danisman N (2008) Role of transvaginal sonography in the diagnosis of retained products of conception. Arch Gynecol Obstet. 277:151-154

9. Dankert T, Vleugels M (2008) Hysteroscopic resection of retained placental tissue: A feasibility study. Gynecol Surg. 5:121-124

10. Smorgick N, Barel O, Fuchs N, Ben-Ami I, Pansky M, Vaknin Z (2014) Hysteroscopic management of retained products of conception:Metaanalysis and literature review. Eur J Obstet Gynecol Reprod Biol. 173:19-22

11. Sellmyer MA, Desser TS, Maturen KE, Jeffrey RB Jr, Kamaya A (2013) Physiologic, histologic, and imaging features of retained products of conception. Radiographics. 33:781-796

12. Capmas P, Lobersztajn A, Duminil L, Barral T, Pourcelot, AG, Fernandez, $H$ (2010). Operative hysteroscopy for retained products of conception: Efficacy and subsequent fertility. Journal of Gynecology Obstetrics and Human. Reproduction. Mar:48(3):151-154.

\section{Publisher's Note}

Springer Nature remains neutral with regard to jurisdictional claims in published maps and institutional affiliations.

\section{Submit your manuscript to a SpringerOpen ${ }^{\circ}$ journal and benefit from:}

- Convenient online submission

- Rigorous peer review

- Open access: articles freely available online

- High visibility within the field

- Retaining the copyright to your article 